\title{
¿QUÉ FRENA LA DEMOCRACIA EN HONG KONG? ENTRE ÉLITES ECONÓMICAS Y SOMBRILLAS AMARILLAS
}

\author{
WHAT PREVENTS DEMOCRACY IN HONG KONG? \\ BETWEEN ECONOMIC ELITES AND \\ YELLOW UMBRELLAS
}

\section{OU S'ARRÊTE LA DÉMOCRATIE À HONG KONG? ENTRE ÉLITES ÉCONOMIQUES ET PARAPLUIES JAUNES}

\author{
Tatiana Andrea Gélvez Rubio \\ Universidad de Southampton \\ tatiana.gelvez@gmail.com
}

Resumen: Hong Kong presenta un caso que pone en cuestión la teoría de modernización de Samuel Huntington. Por una parte, se señala como impedimento el retorno de la soberanía a la República Popular China. Sin embargo, incluso durante el control británico, no desarrolló instituciones democráticas. El presente artículo plantea las implicaciones de la presencia de élites económicas en la política de Hong Kong. Se concluye que, además de la clara intervención china en el consejo legislativo, las protestas de las sombrillas amarillas indican que una parte de la ciudadanía muestra inconformidad con la situación política, buscando alternativas de participación política.

Palabras clave: Hong Kong, democracia, economía política, instituciones, gobernanza local.

ABstract: Hong Kong presents a case that challenges the modernization theory of Samuel Huntington. On the one hand, the return of sovereignty to the People's Republic of China is indicated as an impediment. However, even during the period of British control it did not develop democratic institutions. This paper raises the implications of the presence of economic elites in Hong Kong politics. It concludes that in addition to the clear Chinese intervention in the legislative council, the "yellow umbrellas" protests indicate that part of 
the citizenship are dissatisfied with the political situation, and seek alternatives for political participation.

Keywords: Hong Kong, democracy, political economy, institutions, local governance

\section{Traducción de Gonzalo Celorio Morayta}

RÉsumÉ: Le cas de Hong Kong remet en cause la théorie de Samuel Huntington sur la modernisation. Ce processus se heurte à des obstacles depuis la rétrocession de cette île à la Chine. Il faut dire, pourtant, que Hong Kong n'a point développé d'institutions vraiment démocratiques lorsqu'elle était sous contrôle britannique. L'article parle de l'influence des élites économiques sur la vie politique à Hong Kong et de l'intervention évidente de la Chine au conseil législatif. Les protestations des parapluies jaunes signalent qu'une partie de la population veut exprimer son mécontentement face à la situation politique et trouver des solutions de remplacement.

Mots clés: Hong Kong, démocratie, économie politique, institutions, gouvernance locale

Traducción de BERNARDo MABIRE

Fecha de recepción: agosto de 2018

Fecha de aceptación: noviembre de 2018 
$\mathrm{H}$ ONG Kong es considerada como una de las economías más desarrolladas de Asia, donde ocupa el decimosegundo puesto en el rango mundial del índice de desarrollo humano de $2015 .^{1}$ Se le denomina la economía más libre del mundo, y el centro financiero y comercial más competitivo del planeta. ${ }^{2}$ Sin embargo, ha sido catalogada como una democracia incompleta de acuerdo con el índice democrático de The Economist ${ }^{3}$ y parcialmente libre si se sigue el índice de libertades políticas de Freedom House. ${ }^{4}$ Estas características hacen de este caso un contraejemplo de la teoría de la modernización de Huntington, ${ }^{5}$ según la cual un alto nivel de desarrollo económico conduce a la consolidación de un modelo político democrático.

Bajo el dominio británico, Hong Kong fue uno de los primeros laboratorios del libre mercado en Asia y para finales de los años noventa ya se había constituido el corazón financiero del continente; su bolsa de valores se fundó en 1866 y fue centro de tránsito del comercio internacional, cimentado en los principios del laissez faire, desde y hacia China continental. En consecuencia, su condición como enclave económico y financiero posibilitó el ascenso político de las élites empresariales y financieras. Éstas fueron rápidamente incorporadas en la dirigencia de la isla como una estrategia del gobierno británico para el control del territorio y la estabilidad de los flujos de inversión y comercio; esta estrategia

${ }^{1}$ United Nations Development Program (UNDP), Human Development Report 2016, Human Development for Everyone, UNDP, 2017, en: http://hdr. undp.org/en/2016-report

2 "Hong Kong Index for Economic Freedom 2017" (en línea), The Heritage Foundation, en: http:/ /www.heritage.org-

3 "The Economist Intelligence Unit's Democracy Index 2017", The Economist, en: https://infographics.economist.com/2017/DemocracyIndex/

4 “Hong Kong 2017”, Country Report, Freedom House, en: https:// freedomhouse.org

${ }^{5} \mathrm{~S}$. Huntington, The Third Wave: Democratization in the Late Twentieth Century, Norman, University of Oklahoma Press, 1991. 
sería luego adoptada por la dirigencia china a finales de los años noventa. ${ }^{6}$

A pesar de que Hong Kong no es un Estado soberano, su condición de Región Administrativa Especial le brinda facultades en términos del manejo fiscal y administrativo del territorio, compatibles con el establecimiento de instituciones democráticas. Además, las negociaciones del regreso a la soberanía china del territorio (entre 1982 y 1984) cimentaron los principios de "un país, dos sistemas" y "Hong Kong gobernado por el pueblo hongkonés”, según los cuales se otorgaba autonomía administrativa al territorio, la posibilidad de elegir un jefe de gobierno y un consejo de la ciudad con independencia del gobierno de Beijing por cincuenta años, a partir del regreso a la soberanía china.

Basados en evidencia histórica, autores como $\mathrm{Sing}^{7} \mathrm{refu}-$ tan la idea de que el regreso de la soberanía de Hong Kong a la República Popular China haya representado el principal obstáculo para el desarrollo de instituciones políticas de corte económico en la isla, ya que este argumento desconoce la diversidad de intereses de actores económicos y políticos que confluyen en el desarrollo de la política hongkonesa. A modo de ejemplo, señala que los orígenes de los movimientos prodemocráticos precedieron el inicio de las negociaciones sinobritánicas. Por tanto, si el gobierno británico hubiera tenido voluntad política de consolidar la democracia en Hong Kong, hubiera consolidado instituciones políticas democráticas durante el periodo de control colonial. En este sentido, es preciso preguntarse: ¿cuáles son los actores presentes en el desarrollo político-económico de Hong Kong? y ¿por qué los intereses de estos actores no son compatibles con los de un modelo democrático?

${ }^{6}$ Hong Kong era un punto estratégico para la apertura internacional de Deng Xiaoping, por lo que era vital mantener vigente la experiencia financiera y comercial de la isla tras el retorno de la soberanía.

${ }^{7}$ M. Sing, Hong Kong's Tortuous Democratization: A Comparative Analysis, Nueva York, Routledge Curzon Contemporary China Series 2, 2004. 
En la actualidad, la autonomía otorgada a Hong Kong, establecida en los acuerdos de retorno a la soberanía, se ha puesto en duda con la postulación de candidatos a la elección de jefe de gobierno en Hong Kong, así como las restricciones a la elección por voto directo en los comicios de 2017, que cuestionaron el respeto por el ejercicio de los derechos políticos de los ciudadanos. En consecuencia, las protestas conocidas como "el movimiento de las sombrillas amarillas", liderada por estudiantes y civiles desde 2013, son una manifestación pública de un proceso político democrático de tres décadas. La dirigencia china, por su parte, recuerda el apoyo de los académicos y líderes políticos hongkoneses al movimiento de Tiananmén en 1989, y reconocen tal antecedente como un riesgo para su control del territorio. ${ }^{8}$

Para los líderes de Partido Comunista Chino, el capitalismo de Hong Kong es más que un mercado competitivo: es una economía política dominada por grandes capitalistas, por lo cual, tras la salida de capitales británicos con el traspaso del territorio, los dirigentes chinos aseguraron la continuidad de la economía hongkonesa con el apoyo de las élites empresariales de China continental, a las cuales designaron como miembros del Congreso Nacional del Pueblo y del Comité Político Consultivo de la Asamblea Nacional Popular, lo que generó una alianza público-privada como medida estratégica para garantizar la continuidad de las actividades financieras en un ambiente político estable. ${ }^{9}$ Este esfuerzo muestra que, a pesar de la importancia de ciudades como Shanghái, Shenzhen y Hangzhou como polos de desarrollo comercial, claves en el desarrollo de China, la integración política y económica de Hong Kong y China continental continúa siendo de alta prioridad.

En este contexto, el argumento central del presente documento es que las élites de negocios representan actores

${ }^{8}$ W. Tu, "Implications of the rise of Confucian East Asia", Daedalus, 129 (1), invierno de 2000, pp. 195-218.

9 S. Alvin, Hong Kong's Embattled Democracy: A Societal Analysis, Baltimore, John Hopkins University Press, 1999. 
fundamentales de las dinámicas políticas de Hong Kong, al proteger intereses privados que no necesariamente resultan en un arreglo institucional favorable para el bienestar colectivo. Para ello, analiza las particularidades del sistema político de Hong Kong y detalla, a la luz de los postulados de la teoría de la modernización, ${ }^{10}$ la realidad actual del territorio frente a un paradigma democrático.

El documento se compone de cinco secciones. La primera es la presente introducción. La sección 2 muestra de manera general los planteamientos teóricos relevantes para el caso. La sección 3 es una descripción histórica de la evolución de las instituciones políticas en Hong Kong, y de la representatividad de los partidos y la participación política. La sección 4 analiza tres criterios básicos de la definición de democracia de Robert Dahl, ${ }^{11}$ la situación histórica y actual de Hong Kong y se contrasta con otros países de Asia del Este. Finalmente, se presentan algunas conclusiones.

\section{Planteamientos teóricos}

Con el regreso de la soberanía de Hong Kong a China continental resurge el debate teórico sobre la pertinencia de modelos democráticos en Asia. Por una parte, autores con una perspectiva estructuralista, identificados con la teoría de la modernización, plantean una relación entre el nivel de desarrollo económico y la consolidación de un modelo político democrático. ${ }^{12}$ En este sentido, Margaret $\mathrm{Ng}^{13}$ resalta la idea

${ }^{10}$ Huntington, op. cit.

${ }^{11}$ R. Dahl, Polyarchy: Participation and Opposition, New Haven, Yale University Press, 1971.

12 Loc. cit.; Huntington, op. cit.; R. Barro, "Determinants of democracy", Journal of Political Economy 107 (S6), 1999, pp. 158-183.; D. Acemoglu y J. Robinson, Economic origins of Dictatorship and Democracy, Cambridge, University Press, 2006.

${ }^{13}$ M. Ng, "Why Asia Needs Democracy", Journal of Democracy, vol. 8, núm. 2, pp. 10-23, Project Muse, 1997. 
de universalidad de los principios democráticos y plantea que la democracia garantiza los derechos ciudadanos de participar activamente en la política y el gobierno; por tanto, Asia necesita tanta democracia como Europa o América. De aquí que casos como Taiwán o Corea del Sur muestren claras transiciones a modelos democráticos como un proceso natural hacia la evolución política de estas sociedades.

En contraposición, académicos con una perspectiva culturalista resaltan la influencia del sistema de creencias. En particular, los principios confucianos de la acción colectiva como frenos para el florecimiento de un modelo democrático. ${ }^{14}$ Adicionalmente, se pone en duda la universalidad de los valores democráticos; ${ }^{15}$ por ejemplo, Bilahari Kausikan ${ }^{16}$ plantea que la discusión va más allá de las diferencias entre los valores occidentales y asiáticos. Basado en encuestas de opinión, argumenta que la mayoría de los ciudadanos manifiestan que priorizan el orden y el progreso económico sobre las libertades individuales. ${ }^{17}$ De esta manera, estas perspectivas reviven la discusión en torno al concepto de democracia,

${ }^{14}$ L. Pye y M. Pye, Asian Power and politics: The cultural dimension of authority, Cambridge, MA,. Belknap Press, 1985.; R. Solomon, Mao's Revolution and the Chinese Political Culture, Berkeley, University of California Press, 1971.

${ }^{15}$ Con base en teorías realistas, se plantea que cada país debe encontrar su propia solución a los problemas de gobernanza; en este esquema, la democracia occidental es solamente una variante de diferentes modelos posibles. Por tanto, el concepto de democracia debe mostrar flexibilidad para explicar la diversidad de modelos políticos mundiales. L. Diamond y M. Plattner, Democracy in East Asia, Maryland, The Johns Hopkins University Press, 1998.

${ }^{16}$ B. Kausikan, "Governance That Works", Journal of Democracy, vol. 8, núm. 2, 1997, pp. 24-34.

${ }^{17}$ Este argumento sería altamente cuestionado en el siglo XxI, con el surgimiento de las encuestas de opinión Asia barómetro (www.asianbaro meter.com), que muestran que más de $50 \%$ de las personas encuestadas en 2017 manifiestan que el modelo democrático es siempre preferido a otras formas de gobierno Y. Chu y Y. Chang, "East Asian Democratization in comparative perspective", Routledge Handbook of Democratization in East Asia, Nueva York, Routledge, 2018. 
así como un ejercicio juicioso de la estructura de los sistemas políticos que reflejen las preferencias sociales, poniendo en tela de juicio la supuesta supremacía del modelo de democracia liberal de Occidente como el mejor arreglo político institucional posible. A continuación, se presentan los principales argumentos de cada perspectiva y sus posibles implicaciones en Asia.

\section{Teoría de la modernización}

Los autores más ortodoxos de esta teoría plantean que el nivel socioeconómico es el factor causal más importante de la existencia de un modelo político democrático. ${ }^{18}$ A pesar de que se reconoce como pionero el trabajo de Seymour Lipset, ${ }^{19}$ es realmente seminal la contribución de Samuel Huntington, ${ }^{20}$ en la cual se advierte una tercera oleada de democratización al observar que "entre 1974 y 1990 por lo menos treinta países hicieron una transición hacia la democracia casi doblando el número de gobiernos democráticos". En este sentido, su aporte sienta las bases de la teoría al indicar que la ampliación de la clase media como consecuencia de una mejora en el nivel socioeconómico fue determinante en el incremento de los niveles de educación de la población, lo cual condujo a una cultura política más democrática e incrementos en la eficacia política y confianza interpersonal, materializada en modelos democráticos.

Según Huntington, dentro de los principales obstáculos para el logro de la democracia se encuentra la poca experiencia de las naciones en alternativas políticas participati-

18 Barro, op. cit.; K. Bollen, "Political democracy and the timing of development”, American Sociological Review, 1979, 44, pp. 572-87; Huntington, op. cit.

19 S. Lipset, "Some Social Requisites of Democracy: Economic Development and Political Legitimacy", American Political Science Review 53, 1959, pp. 69-105.

${ }^{20}$ Huntington, op. cit. 
vas. En algunos países, la ausencia completa de periodos democráticos representa una limitante, pues el desconocimiento de los mecanismos participativos se refleja en el poco interés en los ciudadanos. Al mismo tiempo, señala como un desafío que los candidatos cuenten con poca experiencia y conocimiento de estrategias de campaña, elaboración y desarrollo de un programa de gobierno. Para el caso puntual de gobiernos comunistas, el autor precisa que los frenos para el desarrollo de modelos políticos democráticos están en la poca voluntad de los líderes de gobiernos autoritaritos en la difusión de valores democráticos por razones ideológicas. ${ }^{21}$

En contraparte, autores como Stephan Haggard y Robert Kaufman ${ }^{22}$ señalan qué condiciones económicas favorables constituyen un alivio a las presiones políticas, pues un reducido crecimiento económico y precarias condiciones de vida en la población generan apoyo de la opinión pública a movimientos revolucionarios. Para respaldar su argumento, precisan que además de transiciones democráticas, tales como las de Taiwán y Tailandia, que coinciden con periodos de expansión económica previos a la crisis financiera asiática de 1998, también es relevante observar que la evolución política de Filipinas tuvo lugar en medio de una crisis de deuda en 1990. Adicionalmente, como se muestra en la

${ }^{21}$ En el caso de China, el autor precisa: "China continental no cuenta con experiencia en gobiernos democráticos, y la democracia de tipo occidental ha sido apoyada solamente por grupos pequeños de disidentes radicales". En este sentido, los modernizadores de China han sido, en palabras de Nye, "los confucianos leninistas del Partido Comunista y Nacionalista. [...] La etapa de desarrollo de China (en los años ochenta) requirió de un gobierno autoritario para equilibrar el desarrollo económico y las turbulentas demandas de democracia de estudiantes, intelectuales y grupos urbanos de clase media". J. Nye, Jr., "Soft Power: The Means to Success in World Politics", Public Affairs, 2004.

${ }^{22}$ S. Haggard y R. Kaufman, "Democratization, Crisis and the Changing Social Contract in East Asia", en A. MacIntyre, T. J. Pempel y John Ravenhill (eds.), Crisis as Catalyst of Asia's Dynamic Political Economy, Nueva York, Cornell University Press, 2008. 
gráfica 1, para Singapur y China, que experimentaron crecimiento económico durante los años noventa, no se observa una variación significativa en su clasificación de régimen político y continúan entre los menos democráticos de Asia del Este.

Gráfica 1

Transiciones democráticas en países de Asia del Este ${ }^{\mathrm{a}}$

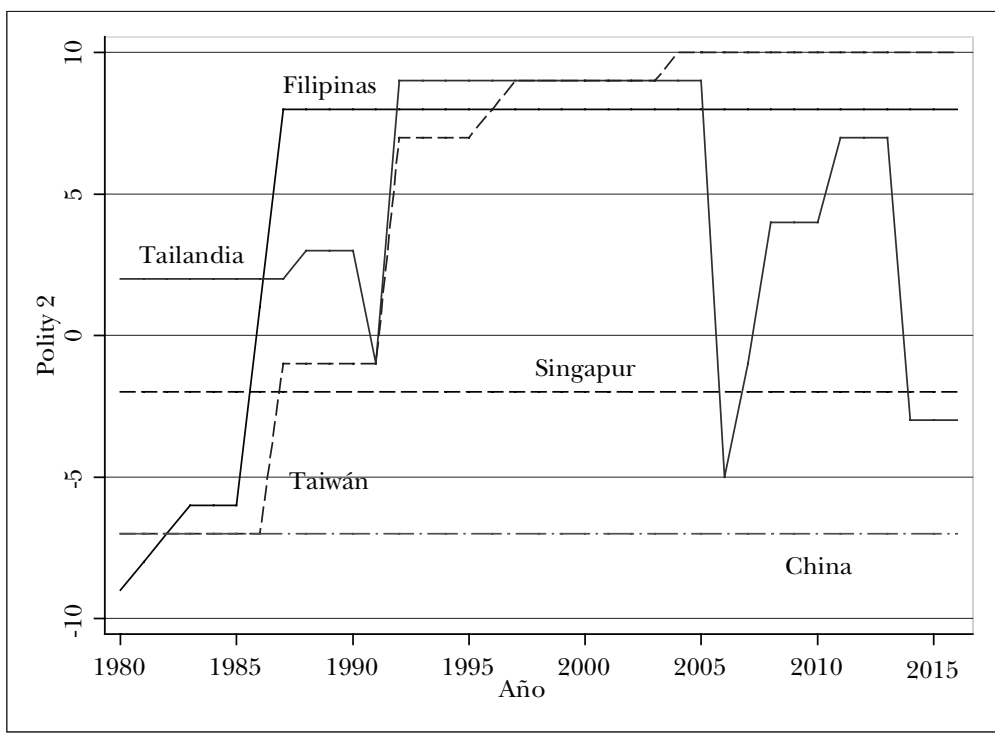

Fuente: elaboración propia con base en datos de Polity IV (Marshall et al., 2019).

${ }^{a}$ El indicador de Polity IV presenta en una escala donde típicamente 6 representa el umbral para un gobierno democrático.

En este sentido, Dahl ${ }^{23}$ indica que si bien hay una relación positiva entre el desarrollo económico y la democracia, no es estrictamente lineal y está restringida a las relaciones de

${ }^{23}$ Dahl, op. cit.; R. Dahl, Democracy and Its Critics, New Haven, Yale University Press, 1989. 
poder. ${ }^{24}$ Adicionalmente, otros autores ${ }^{25}$ advierten que la noción "poliárquica" dahlsiana de la democracia implica que existe un público contestatario que ejerce un control del gobierno, que hace necesaria la participación de la opinión pública en el proceso de elección política.

Siguiendo la idea de que las instituciones desempeñan un papel relevante en los incentivos $-\mathrm{o}$ desincentivos- de diferentes actores en la competencia electoral, ${ }^{26}$ se identifican tres elementos fundamentales para el fortalecimiento de las instituciones políticas: las leyes, la competencia electoral y la presencia activa de la sociedad civil. Con respecto al marco legal, es preciso anotar que se constituye como una estructura sobre la cual se fundamenta el ejercicio de las libertades políticas y civiles, que posibilitan el ejercicio de la libertad de expresión y la creación de organizaciones de la sociedad civil.

En segundo lugar, las elecciones permiten la competencia partidista de forma pacífica, en la cual los ciudadanos expresan su voluntad política. Por tanto, se constituyen como un mecanismo legítimo para obtener el control de los roles políticos. ${ }^{27}$ En el caso de un régimen autoritario, el objetivo de la élite gobernante es estar en el poder, por lo que el gobierno se vale de las instituciones estatales bajo su control para desarrollar ventajas electorales sobre la oposición. ${ }^{28} \mathrm{En}$ consecuencia, las elecciones se dan en condiciones desequi-

${ }^{24}$ Siguiendo esta idea, se descarta que se hayan desarrollado en Asia efectos dominó en las reformas con miras a gobiernos democráticos. En cambio, resalta la importancia de las condiciones estructurales y las causas institucionales. M. Pei, "The fall and rise in democratic East Asia", en L. Diamond y M. Plattner, Democracy in East Asia, Baltimore, The Johns Hopkins University Press, 1998.

${ }^{25}$ Sing, op. cit.; L. Diamond, Developing Democracy: Toward consolidation, Baltimore, MD., The Johns Hopkins University Press, 1999.

${ }^{26}$ M. Olson, N. Sarna y A. Swamy, Governance and Growth. University of Maryland, Baltimore, IRIS Center, 1997.

${ }^{27}$ R. Taagapera, Predicting party sizes: The logic of Simple Electoral Systems, Oxford, University Press, 2007.

${ }^{28}$ S. Levitsky y L. Way, Competitive authoritarianism: Hybrid regimes after the cold war, Cambridge, University Press, 2010. 
libradas, con pocas posibilidades para los candidatos que no pertenecen a la élite.

No obstante, para los miembros de partidos de oposición resulta difícil resistir la tentación de participar en elecciones autoritarias debido a que ocupar un cargo público les permite expandir sus influencias políticas, por lo que, por muy injustas que suelan ser, algunos partidos de la oposición tienen curules en una legislatura controlada por un dictador. ${ }^{29}$ En este contexto, la oposición no refleja una conciencia política, sino motivaciones de supervivencia, desvirtuando la función política de los partidos orientados a la supremacía del bienestar común o a la defensa de un determinado grupo de ideas políticas. ${ }^{30}$

En tercer lugar, el fortalecimiento de la sociedad civil, como plantea Larry Diamond, ${ }^{31}$ es un requisito fundamental para la formación de una cultura política democrática. Incluso académicos de izquierda, como Antonio Gramsci, ${ }^{32}$ señalan la importancia de la sociedad civil como un contrapeso a las clases dominantes y al Estado. A pesar de que el concepto de sociedad civil es amplio y tiene validez en cualquier contexto en el cual exista una causa común, que abarca desde organizaciones de tipo cultural, social y religioso hasta grupos de interés, Jeffrey Alexander ${ }^{33}$ plantea que, en cualquiera de sus manifestaciones, la sociedad civil tiene dos características principales: solidaridad e inclusión, que generan empatía e identidad por determinado grupo.

${ }^{29}$ Levitsky y Way, op. cit.; S. Wong, Electoral Politics in Post-1997 Hong Kong, Springer, Chinese University of Hong Kong, 2015.

${ }^{30} \mathrm{~J}$. Buxton y N. Phillips, Developments in Latin American Political Economy, Manchester, University Press, 1999.

${ }^{31}$ Diamond, op. cit.

32 A. Gramsci, Selections from Prison Notebooks (trad. de Q. Hoare and G. N. Smith), Nueva York, International Publishers, 1971.

${ }^{33} \mathrm{~J}$. Alexander, The civil sphere, Oxford, University Press, 2006. 


\section{La democracia liberal y el confucianismo}

La democracia liberal se entiende como "un sistema político determinado no sólo por elecciones libres y justas y el derecho al voto, sino también por la protección constitucional de los derechos ciudadanos, la libertad de expresión, reunión y religión, el imperio de la ley y la separación de poderes", ${ }^{34}$ y se fundamenta en garantizar el desarrollo político del individuo en todas sus dimensiones. ${ }^{35}$ En este sentido, la implementación de este modelo a contextos culturales que no se enfocan en el individuo pueden hacer que el proceso de democratización sea problemático e insostenible. ${ }^{36}$ En esta misma línea, Lucian Pye ${ }^{37}$ plantea que las condiciones propias de cada cultura hacen que algunas sociedades presenten mayor disposición cultural a fomentar sistemas políticos democráticos mientras que en otras la cultura entra en conflicto directo con este modelo político, por lo que la democratización resulta compleja y prácticamente inviable. ${ }^{38}$

En este debate, el confucianismo como representación amplia de los valores asiáticos tiene posiciones teóricas conflictivas. Por una parte, autores como Huntington ${ }^{39}$ señalan que el confucianismo se constituye como una filosofía antidemocrática, porque las relaciones de poder, en todos los

${ }^{34}$ F. Zakaria, "The rise of illiberal democracy", Foreign Affairs, noviembre-diciembre, 76, p. 6, 1997.

35 Asumiendo que el empoderamiento ciudadano tiene efectos positivos sobre la política, los votantes generan un premio/castigo a los políticos por el desempeño de su gestión pública.

36 B. Ackerly, "Is liberalism the only way toward democracy? Confucianism and Democracy", Political Theory 33, 4, 2005.

${ }^{37}$ L. Pye, The spirit of Chinese politics: A Psychocultural study of the authority crisis in political development, Cambridge, miт Press, 1968.

38 Algunos autores contradicen este argumento afirmando que la herencia confuciana es perfectamente compatible con un sistema político democrático, incluso denominándolo como ademocrático. S. Hu, Explaining Chinese Democratization, Westport, Praeger Publishing, 2000; Tu, op. cit.

${ }^{39}$ Huntington, op. cit. 
niveles de la sociedad, ${ }^{40}$ son incompatibles con modelos políticos deliberativos. Por otra parte, plantea que, ${ }^{41}$ a pesar de que hay evidencia de que el confucianismo influyó en gobiernos autoritarios - por ejemplo, Corea del Sur- y que algunas ideas de la democracia liberal son incompatibles con el confucianismo, el proceso político es dinámico y evolutivo. Por ello, el concepto de "democracia confuciana" es una propuesta promisoria para el desarrollo de instituciones basadas en el mutualismo, más adecuadas con el sistema de valores que promueve la filosofía confuciana. En él, todas las personas son capaces de contribuir a la vida política por tener la virtud "ren", cuyo significado en este contexto es que las instituciones políticas y sociales se desarrollan con el objetivo de lograr la perfección humana. Además, se espera que se creen espacios comunes sobre los deberes públicos como un proceso en continua evolución.

\section{Procesos de democratización}

Zhengxu Wang ${ }^{42}$ plantea que las transformaciones hacia un modelo político democrático constituyen un proceso dinámico y gradual, más que abrupto, de un modelo político hacia otro. En este sentido, el concepto de democratización da cuenta de un proceso de transición, en el cual, para el caso de los países asiáticos, se inició con las mejoras en las condi-

${ }^{40}$ En la sociedad confuciana, cada ser humano se relaciona socialmente bajo cinco vínculos primordiales: gobernado-gobernante, padrehijo, esposo-esposa, hermano mayor-hermano menor, amigo-amigo. Por tanto, cuenta con un limitado margen de maniobra para el ejercicio de las libertades individuales. P. García-Escudero, "Pedagogía confuciana", Desafios, 26 (1), 2014, pp. 57-82.

${ }^{41}$ M. Chang, "Mutual Help and Democracy in Korea", en D. Bell y H. Chaibong, Confucianism for the Modern World, 2003, pp. 90-91.

${ }^{42}$ Z. Wang, Democratization in East Asia: Citizen politics in China, Japan, Singapore, South Korea Taiwan and Vietnam, Nueva York, Cambria Press, 2008. 
ciones económicas además de impactos sociales que generan transformaciones en la estructura de valores morales. ${ }^{43}$ $\mathrm{Al}$ respecto, el autor articula los postulados de la modernización y los valores asiáticos (como se muestra en la figura 1), según la cual los cambios en las condiciones materiales generan transformaciones en tres aspectos: apoyo a la democracia, la expresión propia de valores y la cultura cívica.

\section{Figura 1}

Procesos de democratización

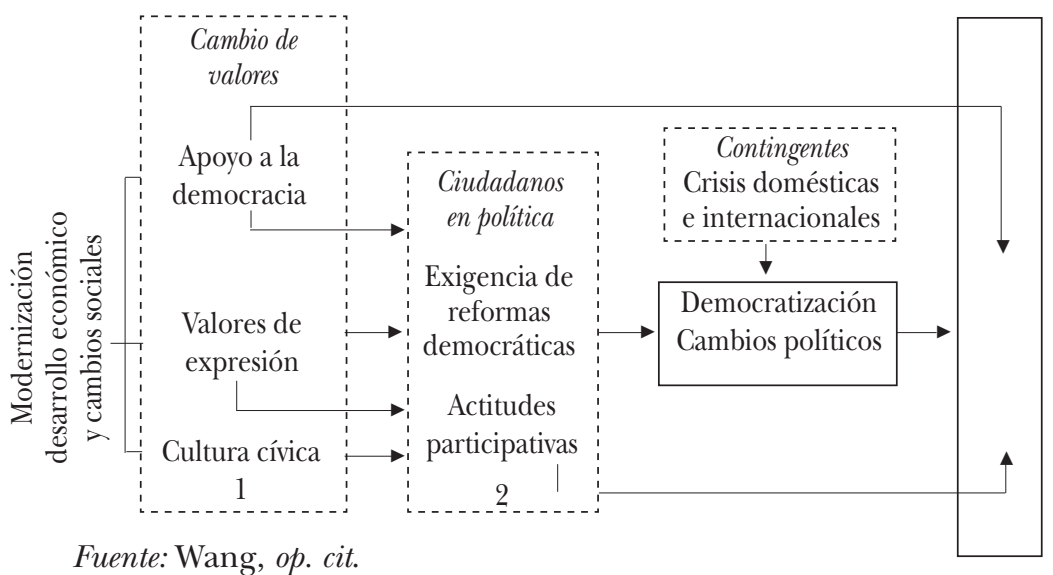

Fuente: Wang, op. cit.

El apoyo a la democracia tiene sus orígenes en la diseminación de este concepto como parte del proceso de globalización. El aumento de conocimiento en una primera etapa hace que los ciudadanos empiecen a familiarizarse con los principios democráticos. Luego de ello, surgirá un descontento con modelos políticos no democráticos y el autor señala que, solamente cuando el descontento se generalice y exista una demanda por un nuevo modelo, se dan manifestaciones de los ciudadanos en búsqueda del cambio. La expre-

${ }^{43}$ Loc. cit. 
sión individual, por su parte, no sólo es importante porque traduce el descontento en demandas de cambio, sino también porque evidencia que existe una actitud proactiva en la política por parte de la sociedad civil. Adicionalmente, la cultura cívica es muestra de una democracia de calidad, la cual se refleja en la confianza, la tolerancia y las acciones participativas que enmarcan acciones directas para generar presión para lograr cambios en el plano político. ${ }^{44}$

Es importante destacar que las exigencias para lograr cambios pueden generar democratización de manera gradual, con flexibilidad de apertura o rigidez del control político, como en el caso de China. Por ejemplo, en Corea del Sur, el descontento general fue lo suficientemente fuerte para acelerar el cambio. Finalmente, la consolidación es el resultado del proceso de democratización; frente a esta etapa del proceso, ésta no se dará necesariamente de manera inmediata y puede haber retrocesos hacia autoritarismos. Por ello, es importante que haya instituciones sólidas que puedan detener a los actores que intenten regresar a modelos autocráticos o dictatoriales, así como redes complejas de ciudadanos que participen de forma activa. ${ }^{45}$

\section{El sistema político en Hong Kong}

Como se mencionó, Diamond ${ }^{46}$ resalta cuatro elementos fundamentales para analizar las instituciones políticas: el marco legal, el sistema electoral, los partidos políticos y la sociedad civil. Con estas condiciones en mente, el autor presenta tres categorías principales para caracterizar las democracias: democracias electorales, liberales y pseudodemocracias. Aunque en las dos primeras categorías la elección del gobierno se

${ }^{44}$ G. Almond y S. Verba, The civic culture: Political attitudes and democracy in five nations, Princeton, University Press, 1984.

45 G. O'Donnell, Transitions from Authoritarian Rule. Prospects for Democracy, 4 vol., Baltimore, The Johns Hopkins University Press, 1986.

46 Diamond, op. cit. 
realiza mediante el sufragio universal, para alcanzar la categoría de democracias liberales es necesario que las elecciones se efectúen en un marco de libertad de expresión, imperio de la ley, cultura liberal y derechos civiles. La pseudodemocracia, por su parte, se entiende como un tipo de modelo político en el cual se incluyen algunos componentes democráticos, como múltiples partidos y libertades civiles básicas, tales como la expresión de prensa, pero no existe capacidad real contestataria al poder.

Con el objetivo de ubicar el gobierno de Hong Kong en este marco conceptual, a continuación se analizan los cuatro elementos planteados por Diamond. Asimismo, se presenta una comparación entre el desarrollo del modelo democrático en Hong Kong con otros países de Asia del Este, tales como Singapur, Corea del Sur y Taiwán.

\section{Marco legal: la Ley Básica}

En el marco de la Séptima Asamblea Nacional Popular, el gobierno de la República Popular China (RPCh), en conjunto con las élites locales, designó a Hong Kong como una Región Administrativa Especial y se promulgó la Ley Básica como la carta política del territorio, que se hizo efectiva el primero de julio de 1997. En este marco legal, se establecieron los principios de su relación con la autoridad central, la estructura política, la administración pública y la legislación económica. Un aspecto al que es necesario prestar atención respecto a esta ley fue el establecimiento de mecanismos mediante los cuales el ejecutivo es comandado por un jefe sin filiación política, sin mecanismos de rendición de cuentas en contraposición al principio de elección popular de los gobernantes. En específico, sobre la elección del ejecutivo, la Ley Básica establece en su artículo 45 lo siguiente:

El ejecutivo de la Región Administrativa Especial de Hong Kong será designado por elecciones o consultas llevadas a cabo 
por comités del gobierno central de la República Popular China. El método de elección se especificará a la luz de la situación existente de la Región Administrativa Especial y de acuerdo con el principio de orden gradual. ${ }^{47}$

Aunque la ley básica establece que el ejecutivo puede ser elegido por sufragio universal, el documento es ambiguo frente al momento y el método de elección de los candidatos. Además, la ley permite interpretaciones arbitrarias con la inclusión del gobierno central en la nominación. ${ }^{48}$ En este sentido, aunque la ley expresa que el ejecutivo será elegido "por representantes del comité de postulación de acuerdo con procedimientos democráticos", el gobierno de Beijing ha dejado claro en repetidas ocasiones que solamente los candidatos "patriotas" que "amen a su país" podrán ser postulados, lo que implica que podría existir veto para candidatos "indeseados".

Se designó un segundo órgano político denominado consejo legislativo (LegCo) en una aparente representación de un equilibrio de poderes. Sin embargo, el LegCo cuenta con menos poderes políticos que el ejecutivo. Por ejemplo, no está facultado para emitir leyes relacionadas con el gasto público, la estructura política y la operación del gobierno (artículo 74). En este sentido, la Ley Básica no busca en la práctica otorgar al legislativo poder de supervisión sobre la gestión de la rama ejecutiva. ${ }^{49}$ No obstante, mantiene algu-

${ }^{47}$ The Basic Law of the Hong Kong Special Administrative Region of The People's Republic of China, 1997 (Ley Básica de la Región Administrativa Especial de Hong Kong).

${ }^{48}$ La vigilancia de Beijing también se explica en virtud de los amplios poderes del ejecutivo, tales como emitir políticas y órdenes ejecutivas (artículo 48,4), postulación de los principales oficiales, incluyendo el comisionado anticorrupción, el director de inmigración, el director de auditorías (artículo 48,5) y la disolución del consejo en tiempos de impasse legislativos (artículo 50).

${ }^{49}$ Es importante mencionar que durante la administración británica tampoco se constituyeron instituciones que garantizaran la rendición de cuentas de la gestión pública. Deng Xiaoping mencionó en más de 
nas facultades, como la de avalar el nombramiento y la destitución de jueces, cuestionar políticas gubernamentales y revocatorias. Frente a la elección del legislativo, el artículo 73 se vale de un lenguaje similar al de la elección del ejecutivo al establecer que:

El consejo legislativo de la Región Especial Administrativa de Hong Kong se constituirá por elección. El método para formar el consejo se especificará a la luz de la situación real de la Región Administrativa Especial, de acuerdo con el principio de orden gradual..$^{50}$

En términos de estructura, el LegCo está integrado por setenta miembros; la asignación de curules tiene dos tipos de circunscripciones: funcionales y geográficas. Las circunscripciones funcionales representan una gran variedad de profesiones, sectores económicos y grupos sociales considerados "cruciales" para el desarrollo de Hong Kong. Las circunscripciones geográficas, por su parte, se relacionan con cinco dis$\operatorname{tritos}^{51}$ y se elegin por voto popular. En la práctica, los miembros de circunscripciones funcionales del consejo legislativo responden a los los grupos de interés a los que representan, mientras que los intereses generales de la ciudadanía quedan limitados a la capacidad de obtener representación por medio de las curules geográficas.

una oportunidad que el concepto de la separación de poderes no se aplicaba para Hong Kong. D. Xiaoping, lun 'Yiguo Liangzhi' (Deng Xiaoping Discusses 'One country two systems'), Hong Kong, Joint Publishing; 2004, p. 56.

${ }^{50}$ Ley Básica, op. cit.

${ }^{51}$ La isla de Hong Kong, Oriente y Occidente de Kowloon, Nuevos territorios de Oriente y Occidente. 


\section{Competencia de partidos y representatividad}

Durante las últimas dos décadas, la participación de partidos pro Beijing ha sido mayoritaria. En específico, se resaltan el Partido Alianza Democrática para el Mejoramiento y Progreso de Hong Kong (DAB), el cual ha predominado durante las seis legislaturas con 17\% de las curules en el LegCo. Además, el Partido Liberal tuvo una mayor presencia en las primeras legislaturas y ha venido disminuyendo su número de escaños en las últimas dos elecciones, pero permanece como una fuerza política importante.

Por otra parte, los partidos prodemocráticos han experimentado una drástica disminución en su participación dentro del consejo. Por ejemplo, el Partido Democrático obtuvo solamente $10 \%$ de las curules, que representa la mitad de los escaños obtenidos en 1998. Adicionalmente, es claro que las circunscripciones funcionales han ayudado a proteger los intereses del gobierno central, al haber sido ocupadas por políticos que claramente están alineados con los intereses de Beijing. En consecuencia, a pesar de la popularidad de los partidos de oposición, en la práctica han tenido posibilidades muy reducidas de estar dentro de las circunscripciones funcionales. Por tanto, la oposición siempre ha sido minoritaria y en la práctica sus votos no han sido determinantes para la toma de decisiones, debido a que la Ley Básica establece una mayoría simple para la aprobación de los proyectos de ley, la cual se alcanza con facilidad con los miembros del consejo pro Beijing y se refuerza con las circunscripciones especiales. ${ }^{52}$

Como se mencionó antes, los líderes chinos buscaban mantener la estabilidad financiera al considerar el territorio un enclave estratégico para la apertura económica, como parte del proceso reformas económicas de Deng Xiaoping. Era claro para la dirigencia que Hong Kong, además de un mercado competitivo, se había constituido en una economía

${ }^{52}$ Wong, op. cit. 
política dominada por grandes capitalistas. ${ }^{53}$ De aquí la importancia de trabajar en conjunto con las élites de negocios dentro del gobierno. La turbulencia generada en los flujos salientes de capital de los grandes hongs, ${ }^{54}$ como Jardine Group y HSBC durante el periodo de transición, fue hábilmente sorteada con el reemplazo de éstas por élites de negocios de China continental, dando así continuidad a la dominación de las élites en la burocracia.

El apoyo de las élites inversionistas de China continental resultaba conveniente, puesto que un sistema autoritario garantiza un entorno político estable para la toma de decisiones de inversión y, por tanto, la cooperación con el gobierno para asegurar estabilidad de largo plazo para sus inversiones se manifiesta en lealtad en el LegCo y en la burocracia del ejecutivo. Tras el regreso de Hong Kong a la soberanía china, los empresarios -en especial los capitalistas chinos- han considerado necesarias las condiciones patronales en la política. De aquí que grandes tycoons fueran designados como parte del equipo en la redacción de la Ley Básica y líderes de las instituciones de transición, miembros del Congreso Nacional del Pueblo y del Comité Político Consultivo de la Asamblea Nacional Popular, lo que generó una alianza público-privada china.

${ }^{53}$ Durante el periodo colonial, la alianza entre el gobierno británico y el sector de negocios permitió a los capitalistas disfrutar de privilegios tales como un bajo nivel de impuestos y escasa regulación gubernamental. Así, los líderes en Beijing eran conscientes de la importancia de la confianza de los inversionistas y de cooperar con la clase capitalista china para llenar el vacío dejado por el éxodo de capitales británicos y mantener la estabilidad del sistema capitalista de Hong Kong.

${ }^{54}$ Los hongs son grandes conglomerados económicos fundados por los británicos durante el periodo colonial en Cantón-China y fungían como bancos mercantiles que facilitaban las transacciones de las empresas que llevaban mercancías a Europa. En la actualidad, algunos se mantienen en el mercado como grandes firmas multinacionales de capital. Dan Waters, "Hong Kong Hong with long histories and British connections", Journal of the Royal Asiatic Society Hong Kong Branch, vol. 30, 1990. 


\section{Implicaciones de política pública}

Un modelo político liderado por élites y poca representatividad de otros grupos sociales ha dirigido una legislación que favorece intereses particulares. Por ejemplo, el esquema individual de visitas, que ha conducido a Hong Kong a ser un centro comercial de productos de lujo para turistas de China continental, ha generado a su vez un proceso de gentrificación y el cierre de tiendas locales, destrucción de barrios residenciales, además de disparar los precios de la propiedad, con lo que ha precarizado la condición de vida de los hongkoneses. Por ejemplo, entre 2013 y 2014, la renta de un apartamento de alrededor de 40 metros cuadrados aumentó en $28.3 \% .^{55}$

Adicionalmente, los permisos del gobierno para desarrollar proyectos inmobiliarios -que luego también otorgaría participación política en las curules de circunscripción especial a los capitalistas en Hong Kong- han permitido la construcción en áreas rurales que facilite la integración con China continental a través de Shenzhen, sin generar proyectos de vivienda social y reduciendo la frontera agrícola, ya escasa, de Hong Kong.

\section{Élites gobernantes y sociedad civil}

Durante el periodo de dominio británico no se avanzó significativamente en crear mecanismos de participación política ciudadana, derechos a la libertad de expresión y a la manifestación pacífica. En consecuencia, a pesar de que el regreso de la soberanía a la República Popular China presentó restricciones a la consolidación de un modelo democrático, realmente la ausencia de una cultura política sólida, de instituciones políticas consolidadas, y la reducida cohesión de la

55 "Official asks Hong Kong to pass controversial pro-China law", BBC Monitoring, 20 de diciembre de 2017. 
sociedad civil son los principales factores que han alejado a Hong Kong de la democracia. ${ }^{56}$

Adicionalmente, es importante resaltar que la conexión entre las élites de negocios y el gobierno es de larga tradición. Desde el establecimiento de la isla como colonia británica, ya era común que se designaran en el gobierno a miembros de las élites para suavizar el control del territorio. Como se muestra en la figura 2, los empresarios y banqueros pasaron a ser parte importante de las élites del poder, al garantizar el funcionamiento de los negocios bajo el control británico.

Gráfica 2

Composición de curules LegCo 1998-2017
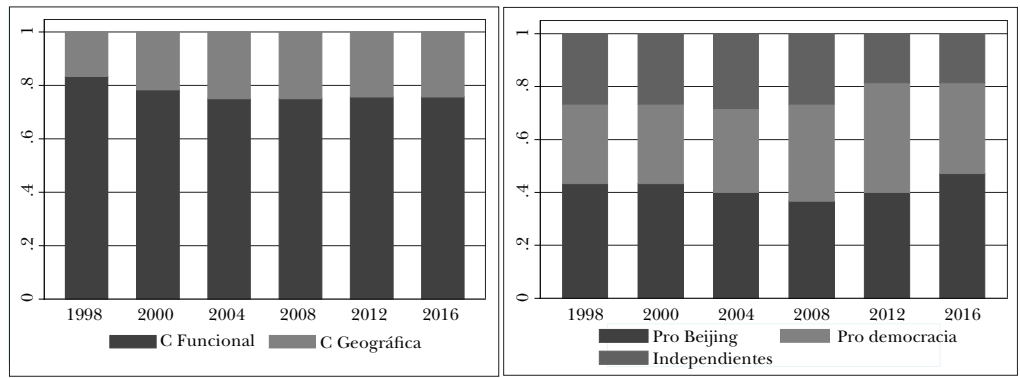

Fuente: elaboración propia con base en resultados electorales de LegCo.

Hong Kong tuvo ligeros avances en la creación de instituciones democráticas hacia los últimos años del dominio británico, debido a la presión internacional sobre los británicos por los incidentes de Tiananmen, como se muestra en la gráfica 4. En consecuencia, el gobierno británico designó a Christo-

${ }^{56}$ H. Kuan y S. Lau, "Political Attitudes and changing in context: The case of Hong Kong”, occasional paper 64, Hong Kong: Institute of Asia Pacific Studies, Chinese University of Hong Kong, 1997. 
pher Patten ${ }^{57}$ como su último gobernador. Patten se presentó como una figura pública con una posición antagónica al gobierno de la República Popular de China e implementó reformas en temas como la edad mínima para votar, las reglas pluralistas para la elección de curules y la ampliación de las circunscripciones funcionales, así como el apoyo en la promulgación de leyes para que los casos de violación a los derechos humanos se juzgaran en tribunales especiales. ${ }^{58}$

GRÁFICA 4

Evolución del indicador de libertades políticas (1980-2016)

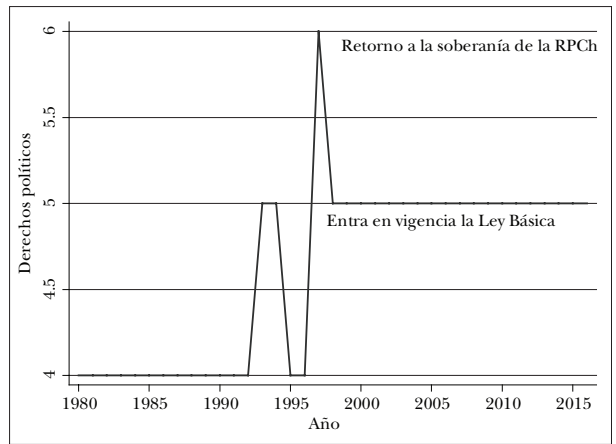

\begin{tabular}{lc}
\hline \multicolumn{1}{c}{ Categoría } & Promedio \\
\hline Derechos políticos & 4.6 \\
Proceso electoral & 3 \\
Pluralismo político & 7 \\
Funcionamiento del & \\
$\quad$ gobierno & 6 \\
Derechos civiles & 2.3 \\
Derechos de asociación & 13.2 \\
Imperio de la ley & 9.2 \\
Derechos individuales & 14.6 \\
\hline
\end{tabular}

Fuente: elaboración propia con base en estadísticas históricas de Freedom House.

De esta manera, el gobierno británico buscaba generar una imagen de "defensa de los valores democráticos" que a su vez creara una percepción positiva ante la comunidad internacional. El gobierno de la RPCh, por su parte, se proponía dar una imagen de compromiso con el discurso de la

${ }^{57}$ Patten era considerado como un político dinámico y entusiasta del Partido Conservador, con una apreciación positiva de la opinión pública. El principal legado de Patten fue el empoderamiento del Partido Democrático (PD), que obtuvo la mayoría en la última legislatura colonial, así como la noción del poder de la participación ciudadana en la política.

58 Wong, op. cit. 
unidad nacional mediante el establecimiento del control del territorio desde el gobierno central de Beijing. En la perspectiva del gobierno chino, estas acciones se proyectaban hacia la opinión pública como una forma de reivindicación a la invasión europea del siglo xix y la reafirmación de la identidad china. ${ }^{59}$

\section{FIGURA 2}

Evolución política de Hong Kong durante las negociaciones

\begin{tabular}{|c|c|c|c|c|c|c|c|c|c|}
\hline \multicolumn{2}{|c|}{$\begin{array}{l}\text { Periodo } \\
\text { autoritario }\end{array}$} & \multicolumn{7}{|c|}{ Fuerzas contrapuestas utilizan su poder de negociación } & $\begin{array}{l}\text { Retro- } \\
\text { ceso }\end{array}$ \\
\hline 1945 & $\begin{array}{l}\quad 1982 \\
\text { Inicio de } \\
\text { la nego- } \\
\text { ciación }\end{array}$ & $\begin{array}{l}1984 \\
\text { Reforma } \\
\text { demo- } \\
\text { crática }\end{array}$ & $\begin{array}{l}\quad 1985 \\
1^{\text {ra }} \\
\text { alianza } \\
\text { demo- } \\
\text { crática }\end{array}$ & $\begin{array}{l}1988 \\
2^{\text {da }} \\
\text { reforma } \\
\text { demo- } \\
\text { crática } \\
\end{array}$ & $\begin{array}{l}1989 \\
\text { Tianan- } \\
\text { mén }\end{array}$ & $\begin{array}{l}1990 \\
\text { Concesio- } \\
\text { nes RPch }\end{array}$ & $\begin{array}{l}1992 \\
\text { Refor- } \\
\text { ma } \\
\text { demo- } \\
\text { crática } \\
\end{array}$ & $\begin{array}{l}1994 \\
\text { Refor- } \\
\text { mas } \\
\text { legisla- } \\
\text { tivas }\end{array}$ & $\begin{array}{l}1997 \\
\text { RPch } \\
\text { sobe- } \\
\text { rana }\end{array}$ \\
\hline
\end{tabular}

Fuente: Sing, op. cit.

El concepto fundamental de que el gobierno es análogo a la familia constituye uno de los imperativos fundamentales del arte chino de gobernar: la preservación de la unidad de China. Los líderes chinos de todas las persuasiones políticas están de acuerdo con el objetivo supremo de mantener a China como una sola, unir todos los territorios históricos y tratar a todas las etnias como si tuvieran lazos naturales con la patria. ${ }^{60}$

Por otra parte, el gobierno chino tenía como prioridad mantener el valor económico y financiero de Hong Kong, que aún en la actualidad sigue siendo indispensable para el siste-

${ }^{59}$ En pro de este objetivo, el gobierno ha permitido aumentar el número de nuevos inmigrantes que constituyen ya $12 \%$ de la población de la ciudad.

${ }^{60}$ Pye y Pye, op. cit., p. 64. 
ma financiero de China continental, al haber demostrado ser más confiable como fuente de financiamiento de capital. Por dar un ejemplo, desde 2012 las compañías chinas han logrado conseguir $\$ 43000$ millones de dólares de capital en ofertas públicas de venta (OPV), mientras que las ofertas de las bolsas de China continental solo alcanzaron $\$ 25000 \mathrm{mi}-$ llones de dólares. ${ }^{61}$

\section{Protestas}

A pesar de la ambigüedad de la Ley Básica, declaraciones del Consejo Nacional del Pueblo (CPANC) en 2013 generaron expectativas respecto al sufragio universal para las elecciones de 2017. No obstante, el 31 de agosto de 2014 el CPANC comunicó la decisión sobre la reforma electoral, estableciendo la continuidad de la preselección de candidatos por un comité y descartando la nominación cívica. Estas circunstancias, condujeron a la ejecución de la etapa final del movimiento Occupy Central, que incluía protestas para bloquear el centro de negocios de Hong Kong tras haber agotado el diálogo con el gobierno para la aprobación del sufragio universal. Las protestas, lideradas por Benny Tai Yiu-ting, iniciaron en marzo de 2013 y a éstas se sumaron políticos de partidos democráticos del LegCo, entre ellos Albert Ho Chun-yan, del Partido Democrático, así como organizaciones de la sociedad civil.

A inicios de 2014, aproximadamente 62000 personas emitieron su voto sobre la reforma constitucional propuesta por Occupy Central en urnas electrónicas; 94\% de los votantes estuvieron de acuerdo con la postulación cívica de candidatos para jefe del ejecutivo y $91 \%$ rechazaban el "filtro" para la postulación de candidatos. Durante diez días en junio del mismo año llevaron a cabo un referéndum extraoficial, en el cual

61 "What China wants. Essays in China's future", The Economist, 2014, en: https://www.economist.com 
votaron 800000 personas. Los resultados mostraron que $88 \%$ de los votantes estaban a favor de elecciones democráticas de legisladores y del veto a reformas políticas que no garanticen "estándares internacionales". A pesar de que este intento reflejaba que existía una intención de tener instituciones más democráticas, para finales de junio, el gobierno de Beijing, mediante un comunicado oficial, declaró ilegales e inválidas las votaciones y acusó a los organizadores de violación del imperio de la ley.

A pesar de que los líderes del movimiento reconocieron que tales estrategias no conducirían a cambiar el curso de acción de Beijing, las protestas continuaron con el boicot de clases por la Federación de Estudiantes y Académicos de Hong Kong. Además, el 28 de septiembre se declaró la campaña de desobediencia civil más grande desde que China tomara el control de la isla en 1997, en la cual se estimó la participación de al menos 80000 personas que protestaron en la plaza del edificio del consejo para luego organizar una ocupación de la vía pública desde Almirante hasta la bahía Causeway. Durante la manifestación, la policía respondió arrojando gases lacrimógenos a los manifestantes, lo que condujo a que éstos abrieran sombrillas para protegerse y, por coincidencia, varias eran de color amarillo, lo que dio origen al nombre: "movimiento de las sombrillas amarillas" para hacer referencia a las protestas. El movimiento no tuvo éxito y sufrió fuertes represalias. Sin embargo, las protestas fueron una clara demostración de la insatisfacción con la forma de gobierno de quienes participaron en ella y alentó nuevos modelos de organización y expresiones democráticas, tales como las urnas electrónicas.

En las elecciones del legislativo en septiembre de 2016, los partidos pro Beijing tuvieron una victoria. Como se muestra en la gráfica 3, los partidos pro Beijing ocuparon $47 \%$ de los escaños, mientras que $34 \%$ correspondió a los partidos prodemocráticos, asegurando los miembros del comité de elección necesarios para la designación de un jefe de gobierno pro Beijing en 2017. En efecto, las elecciones del ejecutivo de 2017 
Gráfica 3

Composición histórica del gobierno (1965-2012)

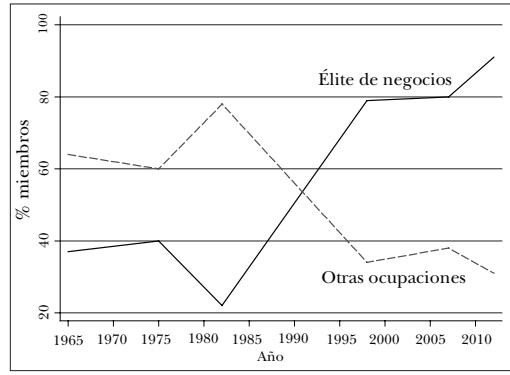

a. Ejecutivo

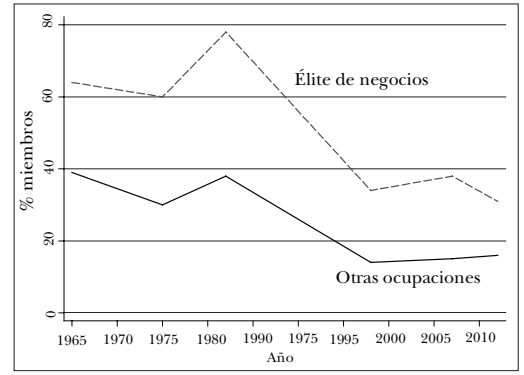

b. Legislativo

Fuente: adaptado de M. Sing, Hong Kong's Tortuous Democratization: A comparative Analysis, Nueva York, Routledge Curzon Contemporary China Series 2, 2004.

que originaron las protestas tuvieron lugar en el mes marzo, cuando un grupo de 1200 miembros del comité de elección dominado por élites pro Beijing eligió como líder del ejecutivo a (Carrie) Lam Cheng Yuet-ngor, con 777 votos y derrotando en las urnas a (John) Tsang Chun-wah, ${ }^{62}$ que obtuvo 365 , y en tercer lugar Woo Kwok-hing, ${ }^{63}$ con 21 votos. De acuerdo con las declaraciones del portavoz de la Oficina de

62 Tsang Chun-wah es el funcionario público con la trayectoria más larga en el gobierno de Hong Kong (más de 32 años). Empezó su carrera como secretario privado de Christopher Patten para luego ser promovido a secretario de Industria y Comercio en 2003. Además, se desempeñó como director de la Oficina del Ejecutivo durante la administración de Donald Tsang. Desde 2007 ha sido Secretario General Financiero de Hong Kong, cargo que ha mantenido durante la administración de Carrie Lam.

${ }^{63}$ Woo Kwok-hing fue un juez jubilado que se desempeñó como vicepresidente del Tribunal Superior de Apelación y jefe de la Comisión de Asuntos Electorales. Actualmente está retirado de la actividad pública, tras enfrentar acusaciones sobre sus propuestas de fusionar el Instituto Educativo de Hong Kong con la Universidad China de Hong Kong, consideradas opuestas a la autonomía de las instituciones educativas y la libertad académica. 
Asuntos del Interior de Hong Kong y Macao, el gobierno central expresó que : "[Carrie Lam] Es una patriota, tiene la confianza del gobierno central, posee capacidad y tiene el apoyo del pueblo de Hong Kong". El comunicado evidencia que se la considera como una fuerte partidaria pro Beijing. Sin embargo, es importante destacar que tiene una amplia trayectoria como funcionaria pública al haber ocupado en 2012 el cargo de jefe de la Secretaría para la Administración, que es considerado el segundo más importante en el gobierno. ${ }^{64}$

Los pasos que ha dado Beijing avanzan hacia el control político completo del territorio, como es claro por la promulgación de nueva legislación durante marzo de 2017, en la cual ${ }^{65}$ se vuelve obligatorio para los candidatos a legislaturas futuras la firma de una declaración que los compromete a conservar la Constitución de China y la Ley Básica, ${ }^{66}$ así como la solicitud de adendas al artículo 23 de la Ley Básica, en la cual se establecerá que Hong Kong “promulgará sus propias leyes para prohibir cualquier acto de traición, secesión, sedición, subversión en contra del gobierno central". ${ }^{67}$ El actual líder del partido DAB, Tam Yiu-chung, y sucesor de Rita Fan Shu Lai-tai, quien además posee las facultades de interpretación de la Ley Básica, manifestó al respecto que: "el movimiento pro independencia, que ha incrementado su popularidad durante los últimos años, vuelve necesaria la promulgación de esta ley". ${ }^{6}$

64 "Biography: Carrie Lam Cheng Yuet-ngor", BBC Monitoring, 26 de julio de 2017.

${ }^{65}$ Algunos miembros del consejo legislativo se negaron a votar a favor de esa legislación, lo cual ocasionó que se invalidaran las candidaturas de Kwok Ka-ki, del Partido Cívico, Yeung Ke-cheong y siete representantes del movimiento Occupy Central de 2014.

66 "Biography: Carrie Lam Cheng Yuet-ngor", art. cit.

67 "Official asks Hong Kong...", art. cit.

68 "Nine Hong Kong democracy activist barred from voting", BBC Monitoring, 13 de diciembre de 2017. 


\section{LA DEMOCRACIA DE HoNg Kong EN}

PERSPECTIVA COMPARADA

La siguiente sección presenta algunas consideraciones comparativas de Hong Kong en relación con las experiencias de Singapur, Corea del Sur y Taiwán. En primer lugar, las dinámicas políticas de Hong Kong guardan ciertas similitudes con Singapur en lo que respecta a gobiernos paternalistas orientados a los negocios. Para el caso particular de Singapur, el primer ministro Goh, en 1995, definió el modelo como una "democracia fiduciaria" 69 que responde a las preferencias de la gente, con base en tres pilares: rendición de cuentas democráticas, orientación de largo plazo y justicia social. Desde su perspectiva, la visión de largo plazo es la diferencia esencial entre el gobierno de Singapur y los postulados de la democracia liberal en su sentido estricto, como se detalló en la sección 2. Empero, autores críticos de este pensamiento señalan como principal falencia del modelo de Singapur, su trato discriminatorio y opresivo con aquellos ciudadanos que presenten una oposición crítica o contraria al gobierno. ${ }^{70}$

Para el caso de Corea del Sur, presentó una ruptura del modelo democrático con Syngman Rhee (1948-1960), seguido de un periodo de gobernanza democrática poco eficaz, que condujo a un sistema de partidos políticos fragmentados y a coaliciones inestables. Luego, durante 1987, fuerzas de la

${ }^{69} \mathrm{El}$ gobierno de Singapur es custodio del bienestar de las personas. Esta responsabilidad le genera opinión independiente para tomar decisiones en pro los intereses de la estabilidad económica de largo plazo, incluso en los casos en que las políticas correctas sean impopulares. C. Goh, "The Singapore Press: Part of the virtuous cycle of a good government and good society" (discurso en Straits Times $150^{\text {th }}$ Anniversary Dinner), Singapur, 15 de julio de 1995.

70 M. Barr, "The Bonsai under the Banyan Tree: Democracy and Democratisation in Singapore". Democratization, 21 (1), 2014, pp. 29-48; G. Rodan, "Embracing electronic media but suppressing civil society: Authoritarian consolidation in Singapore”, The Pacific Review, 16 (4), 2003, pp. 503-524; C. George, "Consolidating authoritarian rule: calibrated coercion in Singapore”, The Pacific Review 20 (2), (2007), pp. 127-145. 
oposición forzaron al gobierno militar a la transición con una realineación de los partidos, que empezó al inicio de la década de los noventa y logró su consolidación en 1992, con la elección de Kim Young-sam como presidente. Se identifican dos similitudes a nivel político entre Hong Kong y Corea del Sur. En primer lugar, ambos casos muestran una activa presencia de la sociedad civil como actor representativo de la participación política de la ciudadanía. En segundo lugar, ambos exhiben la formación de un protosistema de partidos, en el cual existe un partido que claramente muestra dominancia; en el caso de Corea, es el Partido Liberal Democrático; en el de Hong Kong, los partidos pro Beijing.

Finalmente, se destaca la transición democrática de Taiwán, que adoptó una estrategia gradual a la apertura política desde 1970, durante el régimen de Chiang Ching Kuo, ${ }^{71}$ y se consolidó hacia finales de los años ochenta con la participación del Partido Progresivo Democrático en los comicios parlamentarios de 1986. Por otra parte, la mayor presencia de un partido de oposición facilitó ampliar el espectro político a posiciones fuera de las del Kuomintang, o partido dominante. ${ }^{72}$ Una característica común entre la transición hacia la democracia en Taiwán y la realidad actual de Hong Kong es un cambio de modelos en extremo autoritarios hacia otras formas de gobierno, y la naturaleza gradual y progresiva del cambio resulta ser afín al estilo del gobierno chino, con su antecedente más notable en la implementación de las reformas económicas de los años ochenta por Deng Xiaoping.

\section{Conclusiones}

Es clara la intervención china en la interacción entre los actores políticos y empresariales hongkoneses. El carácter atí-

71 El proceso de transición se aceleró luego del fallecimiento de Chiang y la toma de posesión de Lee Teng-hui en 1988.

72 Pei, art. cit. 
pico de Hong Kong hace que no sea posible recurrir a los postulados de la teoría de la modernización en su sentido estricto, como sí es factible en Corea o Taiwán. En ello, su condición de región especial, la ausencia de soberanía y la autonomía económica parcial crean conflictos entre la visión democrática y la realidad política del territorio. En este contexto, como se mostró, el gobierno de Beijing cuenta con una estrategia clara en pro de mantener el estatus de Hong Kong como centro financiero internacional, aspecto que continúa siendo importante para China en su esfuerzo por construir una economía de mercado y, a su vez, garantizar el control del territorio que en 2047 le otorgará la capacidad de decisión frente a los recursos generados por los servicios financieros y comerciales de la isla. Para ello, ha dado continuidad a la presencia de las élites de negocios en el gobierno y en la política de Hong Kong, así como una posición dominante en el ejecutivo y legislativo.

Como se describió en este texto, los orígenes coloniales de Hong Kong no sentaron las bases de un modelo político democrático, pues el objetivo del gobierno británico era garantizar el control del territorio para su funcionamiento comercial, más no la consolidación de un modelo político ni social en el territorio. En este sentido, los cambios favorables para construir un modelo político de mayor participación ciudadana coincidieron con el inicio de la transición al control de la soberanía de la República Popular China, que por medio de la Ley Básica no creó las condiciones para el desarrollo de un sistema de partidos políticos sólidos. Por el contrario, sentó unas reglas del juego que permiten la excesiva intervención del gobierno central en la orientación de las políticas. En términos de equilibrio de poderes, el LegCo no cuenta con facultades legales suficientes para supervisar la gestión del ejecutivo ni para ejercer poder de veto frente a la legislación, al contar con una desequilibrada mayoría de políticos de partidos pro Beijing.

A pesar de lo anterior, es innegable la consolidación de una sociedad civil vibrante, proactiva y con una gran capaci- 
dad tecnológica con fines políticos, como quedó demostrado con las urnas electrónicas utilizadas para el referendo extraoficial. Tampoco es posible para el gobierno ocultar las convicciones de sus ciudadanos, pues desde el día cuatro de junio 1990 asisten al encuentro anual del Parque Victoria, en el corazón de la bahía Causeway, miles de ciudadanos hongkoneses que se unen en una vigilia nocturna para conmemorar a los estudiantes desaparecidos en los incidentes de Tiananmén en 1989. El acto simbólico de encender velas en la noche representa la voz de de los que manifiestan su presencia para hacer parte de la construcción social para las nuevas generaciones.

Es posible señalar que, aunque el modelo político de Hong Kong no cumple con las condiciones básicas de la definición de la democracia de Dahl, los mecanismos expuestos por Huntington en la teoría de la modernización, en los cuales un mayor desarrollo económico conduce a mayor cultura política, se cumplen, puesto que las protestas civiles fueron una muestra de la conciencia de la ciudadanía frente a una precaria representación de sus intereses en la política.

\section{REFERENCIAS BIBLIOGRÁFICAS}

Acemoglu, Daron y James Robinson, Economic origins of Dictatorship and Democracy, Nueva York, Cambridge University Press, 2006. ACKerly, Brooke, "Is liberalism the only way toward democracy? Confucianism and Democracy". Political Theory 33, 4, 2005.

Alexander, Jeffrey, The civil sphere, Oxford, University Press, 2006. Almond, Gabriel y Sidney Verba, The Civic Culture: Political attitudes and democracy in five nations, Princeton, N. J., Princeton University Press, 1984.

Alvin, So, Hong Kong's Embattled Democracy: A Societal Analysis, Baltimore, MD., John Hopkins University Press, 1999.

BARr, Michael, "The Bonsai under the Banyan Tree: Democracy and Democratisation in Singapore”. Democratization, 21 (1), 2014, pp. 29-48. 
BARro, Robert, "Determinants of democracy", Journal of Political Economy 107 (S6), 1999, pp. 158-183.

"Biography: Carrie Lam Cheng Yuet-ngor", BBC Monitoring, 26 de julio de 2017.

Bollen, Kenneth, "Political democracy and the timing of development", American Sociological Review, 1979, 44, pp. 572-87.

Buxton, Julia y Nicola Phillips, Developments in Latin American Political Economy, Reino Unido, Manchester University Press, 1999.

Chang, Yu-tzung y Yun-han Chu, "East Asian Democratization in comparative perspective", Routledge Handbook of Democratization in East Asia, Nueva York, Routledge, 2018.

DAHL, Robert, Polyarchy: Participation and Opposition, New Haven, Yale University Press, 1971.

DAHL, Robert, Democracy and Its Critics, New Haven, Yale University Press, 1989.

Deng, Xiaoping, lun 'Yiguo Liangzhi' (Deng Xiaoping Discusses 'One country two systems'), Hong Kong, Joint Publishing, 2004 , p. 56.

García-Escudero, Pío, "Pedagogía confuciana", Desafíos, 26 (1), 2014, pp. 57-82, doi: 10.12804/desafios26.1.2014.02

George, Cherian, "Consolidating authoritarian rule: calibrated coercion in Singapore", The Pacific Review 20 (2), 2007, pp. 127-145, doi: 10.1080/09512740701306782

GoH, Chok, "The Singapore Press: Part of the virtuous cycle of a good government and good society" (discurso en Straits Times $150^{\text {th }}$ Anniversary Dinner), Singapur, 15 de julio de 1995.

Gramsci, Antonio, Selections from prison notebooks (trad. de Q. Hoare y G. N. Smith), Nueva York, International Publishers, 1971.

Haggard, Stephan y Robert Kaufman, Democratization, Crisis and the Changing Social Contract in East Asia, en Andrew MacIntyre, T. J. Pempel y John Ravenhill (eds.), Crisis as Catalyst Asia's Dynamic Political Economy, Nueva York, Cornell University Press, 2008.

"Hong Kong Index for Economic Freedom 2017" (en línea), The Heritage Foundation, http://www.heritage.org

Hu, S., Explaining Chinese Democratization, Westport, Praeger Publishing, 2000. 
Huntington, Samuel, The Third Wave: Democratization in the Late Twentieth Century, Norman, OK., University of Oklahoma Press, 1991.

Kausikan, Bilahari, "Governance That Works", Journal of Democracy, vol. 8, núm. 2, 1997, pp. 24-34.

KuAn, Hsin-chi y Siu-kai Lau, "Political Attitudes and changing in context: The case of Hong Kong", occasional paper 64, Hong Kong: Institute of Asia Pacific Studies, Chinese University of Hong Kong, 1997.

"Nine Hong Kong democracy activist barred from voting", BBC Monitoring, 13 de diciembre de 2017.

Diamond, Larry, Developing Democracy: Toward consolidation, Baltimore, Johns Hopkins University Press, 1999.

Diamond, Larry y Marc Plattner, Democracy in East Asia, Baltimore, The Johns Hopkins University Press, 1998.

Levitsky, Steven y Lucan Way, Competitive authoritarianism: Hybrid regimes after the Cold War, Nueva York, Cambridge University Press, 2010.

LiPset, Seymour, "Some Social Requisites of Democracy: Economic Development and Political Legitimacy", American Political Science Review, 1959, 53, pp. 69-105.

Marshall, Monty, Robert Gurr y Keith Jaggers, "Polity IV Project: Political Regime Characteristics and Transitions 1800-2016”, Center for Systemic Peace, 2017, http://www.systemicpeace. org/inscrdata.html

Mi-Hye, Chang, "Mutual Help and Democracy in Korea", en Daniel Bell y Hahm Chaibong, Confucianism for the Modern World, 2003, pp. 90-91.

Sing, Ming, Hong Kong's Tortuous Democratization: A comparative Analysis, Nueva York, Routledge Curzon Contemporary China Series 2, 2004.

NG, Margaret, "Why Asia Needs Democracy", Journal of Democracy, vol. 8, núm. 2, 1997, pp. 10-23 (Project MUSE), doi:10.1353/ jod.1997.0029.

Nye JR., Joseph, "Soft Power: The Means to Success in World Politics", Public Affairs, 2004. 
O'Donnell, Guillermo, Transitions from Authoritarian Rule. Prospects for Democracy, 4 vol., Baltimore, The Johns Hopkins University Press, 1986.

"Official asks Hong Kong to pass controversial pro-China law", BBC Monitoring, 20 de diciembre de 2017.

Olson, Mancur, Naveen Sarna y Anand Swamy, Governance and Growth, Baltimore, MD., University of Maryland, Baltimore, IRIS Center, 1997.

PeI, Minxin, "The fall and rise in democratic East Asia", en Larry Diamond y Marc Plattner, Democracy in East Asia, Baltimore, The Johns Hopkins University Press, 1998.

Pye, Lucian, The spirit of Chinese politics: A Psychocultural study of the authority crisis in political development, Cambridge, MIT Press, 1968.

Pye, Lucian y Mary Pye, Asian Power and politics: The cultural dimension of authority, Cambridge, Belknap Press, 1985.

RoDAN, Garry, "Embracing electronic media but suppressing civil society: Authoritarian consolidation in Singapore", The Pacific Review, 16 (4), 2003, pp. 503-524.

Shaohua, Hu, Explaining Chinese Democratization, Westport, Praeger Publishing, 2000.

Solomon, Richard, Mao's Revolution and the Chinese Political Culture, Berkeley, University of California Press, 1971.

TAagaPera, Rein, Predicting party sizes: The logic of Simple Electoral Systems, Oxford, University Press, 2007.

"The Economist Intelligence Unit's Democracy Index 2017", The Economist, https://infographics.economist.com/2017/Demo cracyIndex/

Tu, Weiming, "Implications of the rise of Confucian East Asia", Daedalus, 129 (1), invierno de 2000, pp. 195-218.

Wang, Zhengxu, Democratization in East Asia: Citizen politics in China, Japan, Singapore, South Korea Taiwan and Vietnam, Nueva York, Cambria Press, 2008.

WATERs, Dan, "Hong Kong Hong with long histories and British connections", Journal of the Royal Asiatic Society Hong Kong Branch, vol. 30, 1990. 
"What China wants. Essays in China's future", The Economist, 2014, https://www.economist.com

Wong, Stan, Electoral Politics in Post-1997 Hong Kong, Springer, Chinese University of Hong Kong, 2015.

Zakaria, Fareed, "The rise of illiberal democracy", Foreign Affairs, noviembre-diciembre 76, 6, 1997.

Instrumentos jurídicos, informes y reportes

"Hong Kong 2017", informe de país, Freedom House, https:// freedomhouse.org

The Basic Law of the Hong Kong Special Administrative Region of The People's Republic of China, 1997, https://www.basiclaw. gov.hk

United Nations Development Program (UndP), Human Development Report 2016, Human Development for Everyone, UNDP, 2017, http://hdr.undp.org/en/2016-report 
